\title{
The Modernization of Malay Food Ingredients: A qualitative investigation
}

\author{
Mohd. Shazali Md. Sharif ${ }^{*}$, Norazmir Md. Nor ${ }^{2}$, \\ Ahmad Esa Abdul Rahman ${ }^{1}$, Khairunnisa Mohamad Abdullah ${ }^{1}$ \\ ${ }^{1}$ Faculty of Hotel and Tourism Management, Universiti Teknologi Mara, 42300 Puncak Alam, Selangor, Malaysia \\ 2 Faculty of Health Science, Universiti Teknologi Mara, 42300 Puncak Alam, Selangor, Malaysia
}

\begin{abstract}
This paper attempts to provide and insight into the modernization of Malay food ingredients within Malay communities. Its approach is sociological, using qualitative method of interview and observation, inquiring into the usage of modern food ingredients in the preparation of Malay dishes. Focusing on a small group of consumers in Puncak Alam, Selangor, the findings indicate that the motivation behind choosing modern food ingredients is to save cooking preparation time while improving nutrient intakes.
\end{abstract}

(C) 2016. The Authors. Published for AMER ABRA by e-International Publishing House, Ltd., UK. This is an open access article under the CC BY-NC-ND license (http://creativecommons.org/licenses/by-nc-nd/4.0/).

Peer-review under responsibility of AMER (Association of Malaysian Environment-Behaviour Researchers), ABRA (Association of Behavioural Researchers on Asians) and cE-Bs (Centre for Environment-Behaviour Studies), Faculty of Architecture, Planning \& Surveying, Universiti Teknologi MARA, Malaysia.

Keywords: modernizations; traditional food; Malay food; food ingredients

\section{Introduction}

Modernization is a universal phenomenon and closely associated with globalization and industrialization. It has influenced and altered every facet of human life from traditions, rituals, norms, and daily activities. From a culinary perspective, the modernization of food ingredients has some positive impacts in simplifying and expediting the preparation of meals in the domestic setting. Also, a series of socio-demographic factors such as urbanization upgrades, increased purchasing power, level of education, the number of individuals per household and stylization of consumption, all contribute to the modernization of food ingredients (Osborn, 2015).

Ingredients form part of recipes and contribute to the specific characteristic and flavour of foods (Sharif, Zahari, Nor, \& Muhammad, 2013). Relatively, traditional food ingredients are closely associated with tradition and nature

\footnotetext{
* Corresponding author. Tel.: +6-03-3258 7695

E-mail address: shazali@salam.uitm.edu.my
}

2398-4287 @ 2016. The Authors. Published for AMER ABRA by e-International Publishing House, Ltd., UK. This is an open access article under the CC BY-NC-ND license (http://creativecommons.org/licenses/by-nc-nd/4.0/).

Peer-review under responsibility of AMER (Association of Malaysian Environment-Behaviour Researchers), ABRA (Association of Behavioural Researchers on Asians) and CE-Bs (Centre for Environment-Behaviour Studies), Faculty of Architecture, Planning \& Surveying, Universiti Teknologi MARA, Malaysia.

DOI: http://dx.doi.org/10.21834/e-bpj.v1i3.367 
and thus reflect the identity of a particular culture. However, in this contemporary era, many traditional food ingredients are no longer available in its traditional form (Sharif, Nor, Zahari, \& Muhammad, 2015a). Some ingredients come in a different shape while some in a modern packaging. The innovations of traditional food ingredients involve technology development and adoption where modernization extensively shapes the production, processing and the distribution (Sharif, Nor, Zahari, \& Muhammad, 2015b).

Although anecdotal evidence suggests similar trend in Malaysia, little has been researched on the modernization aspect of Malay food ingredients. A great deal of research attention continues to be focused on the modernization of traditional foods rather than the ingredients (Muhammad, Zahari, Abdullah, \& Sharif, 2015; Sharif et al., 2015b; Sharif et al., 2013). The current study is to explore the usage modern Malay food ingredients in the market and the motivation for using them.

\section{Food Ingredients}

Food ingredients have served useful functions in a variety of ways such as to preserve, flavour, blending, thickening and colouring, and have played an important role in reducing serious nutritional deficiencies among consumers (Akashe \& Gaonkar, 2014). In mid-century, as the population began to concentrate in cities, it became more important to rely on sophisticated food processing and preservation technologies, including the use of specific food ingredients, to provide consumers with the wide range of safe, affordable and convenient foods (Hendrich, 2015).

Rulis and Levitt (2009) specified that Food and Drug Administration (FDA) have listed thousands of ingredients that are being used to make foods at home such as sugar, baking soda, salt, vanilla, yeast, spices and food colouring. According to Akashe and Gaonkar (2014), food choice factors vary according to life stage and the power of one factor will vary from one individual or group of people to the next. Factors include biological and physical determinants, cost, meal pattern, accessibility and the influence of social class, cultural and setting. Religion is another important determinant in influencing food selection. For instance, halal products are the only permissible products that can be consumed by Muslim population all over the world (Jahangir et al., 2016). With the application of modern technology in food ingredients production, Muslim consumers are curious to determine whether food ingredients especially meat products derived from Halal source do not contain any traces or material of non-Halal origin. Such by-products may include the fat, blood and ingredients for gelatine and emulsification. As suggested by Griffiths, Abernethy, Schuber, and Williams (2009), public standards criteria of food ingredient quality must ensure that stakeholders, including manufacturers, distributors, exporters, importers, regulators, and, consumers should know that a food ingredient possesses suitable quality attributes.

\section{The Method}

The study employed a qualitative method research approach in identifying consumers' needs, perceived values, perceptions, and behaviour. To capture the language as well as imagery customers use to describe and relate to a product, service or brand, interviews and observations were utilized and conducted at Tesco hypermarket in Puncak Alam, Selangor. Ten Malay respondents residing in urban areas were randomly selected for the interview and observation. They were approached in the hypermarket and asked to participate in the study. After permission was granted by the selected potential respondents were interviewed and asked to comment on Malay food ingredients related issues. The types of food ingredients selected and purchased by the respondents were also observed during the interviews. All sessions were audio-recorded, transcribed, translated and reported. The informant for this study are divided into three generations; mothers (age between 50 to 60 years old), working women (age between 20 to 40 years old) and single male students (22 years old). 


\section{Findings and Discussion}

Based on the results, which made by the people that live in the urban area are mostly dependent on the food technology to prepared food. Besides that, an urbanization's people would choose and mostly buy ready to eat food rather take the times to cooked for themselves which for them modern food is more convenient and simple to be prepared. In addition, to prepare traditional food, the most concerning part are the raw ingredients. With all the obstacles and challenges, such as a working mother does not have a proper time to prepare the meal, shelf life of the certain products, and ability to access the seasonable food. Thus, modernization of the food ingredient leads for the dumping and increasing of demands for modern food that are convenient that reduce the interest in people in the urban area to prepared food using the traditional ingredient or preparation

\subsection{Informants profiles}

Table 1: Informants' profile

\begin{tabular}{cccccc} 
Informant & Age & Education level & Occupation & Status & Place of Origin \\
\hline Mother & 42 & Diploma & Housewife & Married & Melaka \\
Student $(F)$ & 21 & Matrix & - & Single & Kuala Lumpur \\
Student $(F)$ & 24 & Diploma & - & Married & Kedah \\
Mother & 35 & Degree & Officer & Married & Kuala Lumpur \\
Mother & 33 & Degree & Manager & Married & Kuala Lumpur \\
Mother & 45 & SPM & Housewife & Married & Johor Bharu \\
Student $(M)$ & 22 & Diploma & - & Single & Kuala Lumpur \\
Student $(F)$ & 19 & Foundation & - & Single & Perak \\
Student $(M)$ & 21 & Diploma & - & Single & Terengganu \\
Mother & 39 & Master & Lecturer & Married & Selangor \\
\hline
\end{tabular}

A total of ten informants were involved in the study. Half of the informants are married women with children, and another half is single students. Two of the married women are housewives while the others are working women. These mothers are between the ages of 30 and 45 years old and the students are between the age of 18 and 25 years old. Their profiles are simplified and presented in Table 1.

\subsection{Types of Malay food ingredients}

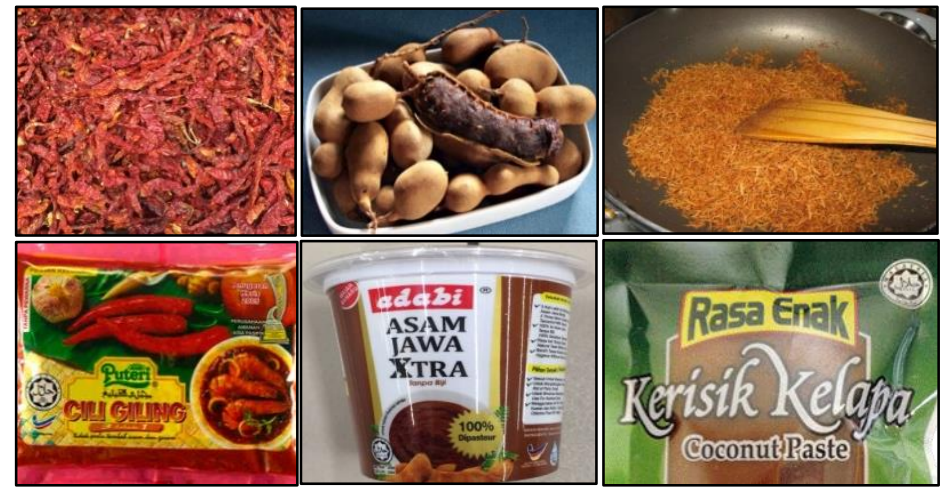

Figure 1: The three pictures on the top row are traditional Malay food ingredients in their original form. The three ingredients at the bottom row are the same ingredients but in a processed and convenient form. 
There are several forms of Malay food ingredient in Malaysia and can be divided into three category such as liquid, solid (paste) and powder. The most common food ingredients used by Malaysians are those in the form of liquid and paste. For instance, food ingredients such as chilli paste, coconut paste, and tamarind paste are widely being used in the preparation of Malay dishes. Using these kinds of ingredients usually result to less preparation and time spends in the kitchen. These traditional food ingredients but in a modern form have greatly eliminated the some tedious preparation techniques such as cleaning and grinding. Thus, it can be said that the modernization of traditional food ingredients have some positive impacts especially to the working mothers for them to prepare meals at home.

Besides paste, various traditional food ingredients are now available in liquid form. For instance, canned coconut milk is now the preferred form used in the preparation of Malay dishes such as curry. Additionally, many of these liquid food ingredients such as coconut milk are preferred over the basic traditional food ingredients because there are usually fortified with vitamins and minerals. Currently, the market is flooded with numerous ready pressed coconut milk brands packaged in various sizes of cans or boxes which increase and optimize the shelf life and quality of the ingredient.

Many home cooks utilize modern food ingredients for easy and simple cooking because it reduces the time spent preparing foods in the kitchen. For example, ready-made stocks or bases eliminate the various processes involve in the preparation of traditional stocks such as deboning and boiling. Nonetheless, the usage of modern food ingredients is negatively impacting the local culinary traditions. Traditional culinary technique and equipment such as grinding with pestle and mortar have been forgotten. Some traditional culinary apparatus such as kukur kelapa (coconut grater) is merely abandoned and has lost its functionality in the Malay kitchen. From a culinary heritage management perspective, it is important to preserve traditional characteristics of a cuisine like culinary technique and equipment because they mirror the identity of a cuisine.
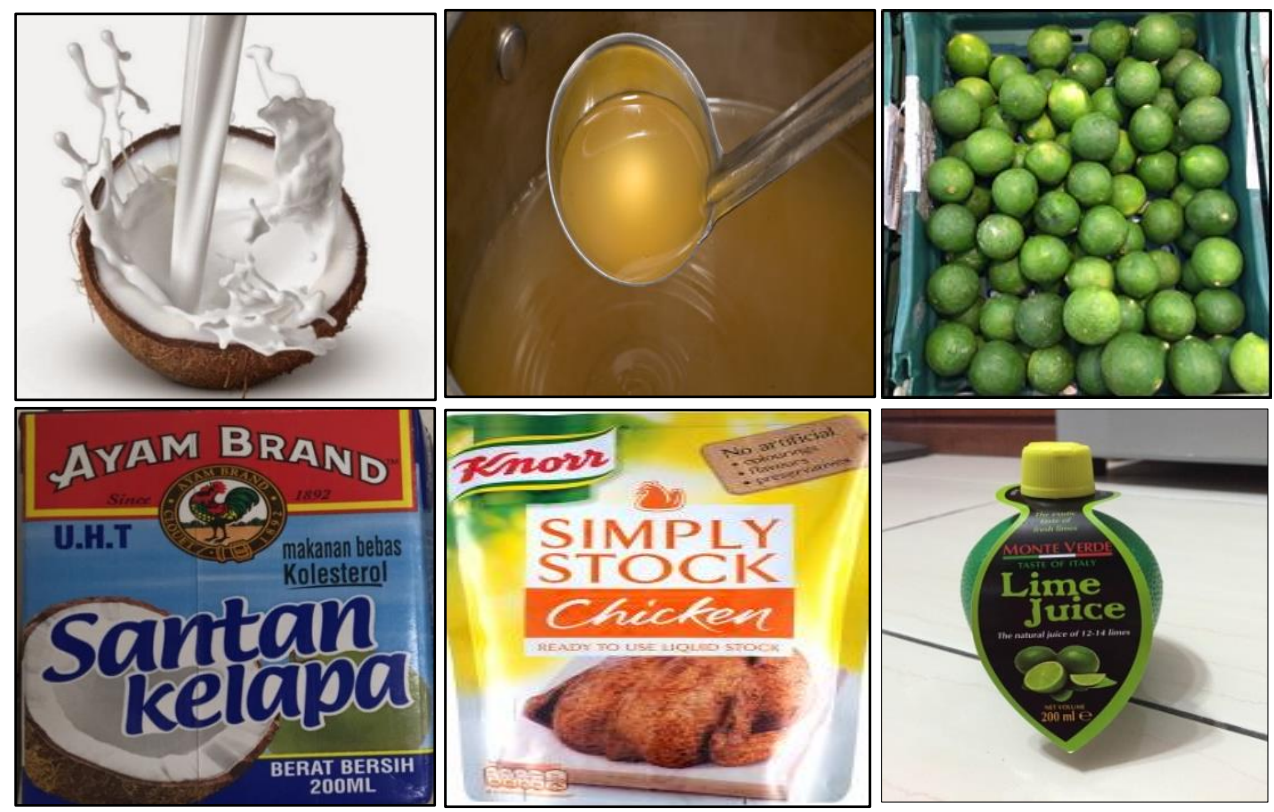

Figure 2: The three pictures on the top row are food ingredients in their original form. The three ingredients at the bottom row are the same ingredients but in a processed and convenient form. 


\subsection{Factors affecting the selection of modern Malay food ingredients}

Based on information gathered, the selection of modern Malay food ingredients is higher among married women with children and students. They opt for modern Malay food ingredients for daily cooking because these ingredients are quick and convenient to use. Nearly $80 \%$ of the informant noted that modernization helps a lot in easing the cooking process. The other $20 \%$ mentioned that they still prepare food the traditional way. These informants are mainly housewives, which have ample time to prepare food using traditional technique and method. Age also plays an important role in the selection of modern Malay food ingredients. Informants age 40 years old, and above tend to choose traditional over modern food ingredient. Most of the informants mentioned that they wouldn't want to lose the originality of their heritage and, therefore, are more likely to use food ingredients in their basic form.

The selection of food ingredients depends on certain factors such as minimal preparation time, cutting requirement, availability of seasonal food, and longer shelf life. Moreover, the majority of the informants note that modern food ingredients have similar flavour quality to the traditional food ingredients. Therefore, the usage of the former is less likely to alter the authentic flavour characteristic of traditional foods.

Additionally, the informants are aware of the usage of chemical substances in the production of modern food ingredients to promote longer shelf-life. Although some informant commented that the flavours of such modern food ingredients are less superior to the original ingredient, they are willing to compromise flavour for convenience. For example, the informants state that they use blended chillies (chili paste) bought at the hypermarket instead of using homemade blended chillies for making sambal dishes. Although they admit that the flavour of sambal dishes made using, modern blended chillies are less superior. They will still use modern food ingredients because of the convenience of the product which makes the preparation of sambal dishes is much easier and faster. As a result, ready to use or modern food ingredients have become a mainstay at many of the informant's kitchen. However, the usage of modern food ingredients varies according to the informants working background. Apparently, housewives have more time to spend cooking at home. Therefore, they prepare most of their food ingredients from scratch and are less likely to use modern food ingredients. For instance:

As a working mother, I am so busy and I do not have enough time to prepare the meal. But with the help of modern food ingredients, cooking process is much easier and less time consuming. Although the price is quite expensive, it does not matter anymore as long as it provides advantages. The flavour is different, yes. But I can alter the taste to preference.

$$
\text { (Working Mother) }
$$

I am a housewife, and I usually have an extra time to make my ingredient from the scratch. Modernization makes people forget about the originality of food. I prefer traditional food ingredient over modern food ingredient. Food taste much better with traditional ingredients even when they are time consuming to prepare.

(Housewife)

I am a student, thus I am busy with my class schedule from morning to evening. Cooking for me would be hard as I am not really diligent. I prefer modern food ingredients for cooking. The taste is not that bad and I do not really take it into account as my time is important that anything else.

(Student)

\subsection{Modernized food ingredients}

Modernization of food ingredients is positively perceived by the informants regarding their convenience. For working mothers, the usage of modern food ingredients is important for reducing of both the amount of time and effort needed in preparing home meals. More important, some of the ingredients are viewed as nutritious because 
they have been fortified with vitamins and minerals. Therefore, they can put less effort into preparing extra dishes such as vegetables or fruits for meals. Some argue that serving of fruits or vegetables for meals does not necessarily means that they are providing healthy meals for the family. The prolonged cooking and excessive preparation of the ingredients may also harm the nutritional content of the food. The informants also commented that using ingredients such as fruits and vegetable does not necessarily means these ingredients are more superior in quality or nutritional content. They argued that some of these ingredients are imported and took days or weeks to reach the country, therefore, their freshness and quality is arguable. The informants added that this was another reason for them to use modern food ingredients. These ingredients have longer shelf life and the added nutritional values remain.

\subsection{Time saving ingredients}

Food preparation is routine that takes place right before cooking and after the purchasing of food ingredients. Consist of several steps; it may include cleaning, cutting, trimming, blanching and more. According to the informants, for working individuals, the usage of modern food ingredients is important for reducing both the amount of time and effort needed in preparing home meals. Some food ingredients such as the traditional blended chillies and lime juice require several preparation techniques before they can be used for cooking. Therefore, the usage of modern preprepared blended chilies and bottled lime juice is more suitable for those who are living a hurried and hectic urban lifestyle but still want to prepare meals at home.

The increasing number of urban population demands more products and services that are convenient and timesaving to cope with their busy lifestyle. Anecdotal evidence shows that modernized food products such as frozen, canned and packaged food are increasing in supply at hypermarkets and supermarkets in urban areas. This hassle free modern food ingredients are replacing the usage of traditional food ingredients in the preparation of Malay dishes. The usage of modern food ingredients has contributed to the continuation of the production of traditional dishes in urban areas. Some dishes that are tedious and complicated to prepare can now be easily prepared without having to spend too much time in the kitchen.

The results indicate that the usage of modern food ingredients benefits the informants mainly in term of reducing the time required for preparing meals at home. For instance, the usage of ready-made chicken stock or cube home cooks the most can save up to 5 hours of preparation time. Chicken stock and other types stock are stapled ingredients usually used in the preparation of chicken rice and soups. Another significant modern food ingredient is kerisik (pounded toasted grated coconut paste). Kerisik is a vital ingredient during festive season used in the cooking of festive food called rendang (spicy meat dish braised in coconut milk and ground spice paste). Producing kerisik is a long and tedious process. The grated coconut first needs to be pan toasted over low heat until the general distribution of the coconut is golden brown. Then the toasted coconut needs to be pounded into an oily paste. Kerisik is not the only ingredient that requires a long pre-preparation process in producing rendang. Other ingredients include blended chillies, tamarind juice and coconut milk, and all these ingredients have to go through several prepreparation processes before they can be used for cooking. Overall, dishes like rendang require a significant amount of ingredients pre-preparation time excluding cooking time. The usage of modernized food has greatly contributed to the reduction of the overall cooking time for not only rendang but also many other Malay dishes.

\section{Conclusion}

The growing presence of convenience, simplified and pre-prepared food ingredients in the market all demonstrate the significance of modernized food ingredients in the preparation of food. The findings indicate the important role modernization plays in determining food choices, in particular on the usage of modern food ingredients in the preparation of home meals among the study population. The main advantage of using modern food ingredients is time saving. Modern food ingredients have great benefits each informant which consist of housewives, working women, single men and students especially in coping with their hurried lifestyles. Little time and effort are required to produce meals at home through the usage of modern food ingredients especially in 
producing traditional Malay dishes. Moreover, modern food ingredients are perceived by the informant as being nutritious. Enhanced or fortified food ingredients are praised for their nutritional content, thus reducing the need to produce multiple dishes for a balanced meal.

Nonetheless, the dependence on modern food ingredients may lead to the deskilling of traditional Malay food preparation and eventually the loss of culinary heritage and identity. Although, modern food ingredients are relevantly important in coping with today's contemporary lifestyle, the traditional culinary techniques and methods in food preparation are still relevant in assuring the continuation of local traditions. Therefore, it is important to use traditional techniques and methods of preparing Malay food ingredients at the very least during festive season and shall be handed down to the younger generations.

\section{Acknowledgement}

This research was funded by the Ministry of Higher Education, Malaysia through Universiti Teknologi MARA under RAGS grant: 600-RMI/RAGS 5/3 (179/2012). The contributions of HS227/5 students in this study is acknowledged. Thank you, Raja Syakilla Raja Noor Azman, Asmah Zatulnakim Othman and A'in Syahira Mispani (HS227/5 students, academic year 2015/16).

\section{References}

Akashe, A., \& Gaonkar, A. G. (2014). Taste-Masking and Controlled Delivery of Functional Food Ingredients. In A. G. Gaonkar, N. Vasisht, A. R. Khare \& R. Sobel (Eds.), Microencapsulation in the Food Industry (pp. 523-532). San Diego: Academic Press.

Griffiths, J. C., Abernethy, D. R., Schuber, S., \& Williams, R. L. (2009). Functional food ingredient quality: Opportunities to improve public health by compendial standardization. Journal of Functional Foods, 1(1), 128-130. doi: http://dx.doi.org/10.1016/j.jff.2008.09.012

Hendrich, S. (2015). Novel Foods. In B. Caballero, P. M. Finglas \& F. Toldrá (Eds.), Encyclopedia of Food and Health (pp. 79-83). Oxford: Academic Press.

Jahangir, M., Mehmood, Z., Saifullah, Bashir, Q., Mehboob, F., \& Ali, K. (2016). Halal status of ingredients after physicochemical alteration (Istihalah). Trends in Food Science \& Technology, 47, 78-81. doi: http://dx.doi.org/10.1016/j.tifs.2015.10.011

Muhammad, R., Zahari, M. S. M., Abdullah, K. M., \& Sharif, M. S. M. (2015). Young Generation Practices on Malaysian Ethnic Festival Foodways. Procedia - Social and Behavioral Sciences, 170, 300-307. doi: http://dx.doi.org/10.1016/j.sbspro.2015.01.040

Osborn, S. (2015). Labelling relating to natural ingredients and additives. In P. Berryman (Ed.), Advances in Food and Beverage Labelling (pp. 207-221). Oxford: Woodhead Publishing.

Rulis, A. M., \& Levitt, J. A. (2009). FDA'S food ingredient approval process: Safety assurance based on scientific assessmen. Regulatory Toxicology and Pharmacology, 53(1), 20-31. doi: http://dx.doi.org/10.1016/j.yrtph.2008.10.00

Sharif, M. S. M., Nor, N. M., Zahari, M. S. M., \& Muhammad, R. (2015a). Following Mothers to the Wet Market: The Significant Benefits Gain by Young Generations. Procedia - Social and Behavioral Sciences, 170, 197-205. doi: http://dx.doi.org/10.1016/j.sbspro.2015.01.029

Sharif, M. S. M., Nor, N. M., Zahari, M. S. M., \& Muhammad, R. (2015b). What Makes the Malay Young Generation had Limited Skills and Knowledge in the Malay Traditional Food Preparation? Procedia - Social and Behavioral Sciences, 202, 152-158. doi: http://dx.doi.org/10.1016/j.sbspro.2015.08.218

Sharif, M. S. M., Zahari, M. S. M., Nor, N. M., \& Muhammad, R. (2013). How could the Transfer of Food Knowledge be Passed down? Procedia Social and Behavioral Sciences, 105, 429-437. doi: http://dx.doi.org/10.1016/j.sbspro.2013.11.045 